\title{
Convergent evolution of jaws between spinosaurid dinosaurs and pike conger eels
}

\author{
Romain Vullo, Ronan Allain, and Lionel Cavin \\ Acta Palaeontologica Polonica 61 (4), 2016: 825-828 doi:http://dx.doi.org/10.4202/app.00284.2016
}

Spinosaurs represent a group of peculiar theropod dinosaurs that have often been described as "crocodile-mimic", predominantly fish-eating predators, and recently claimed to have been semi-aquatic animals. Here we report a suite of craniodental characters unexpectedly shared by spinosaurs and pike conger eels. Pike conger eels are predatory, mainly piscivorous bottom-dwelling anguilliform fishes that inhabit marine and brackish environments. These two groups of dinosaurs and fishes show a mediolaterally compressed, elongated rostrum, a terminal "rosette" bearing enlarged teeth in both upper and lower jaws, and a notch posterior to the premaxillary "rosette" characterized by the presence of reduced teeth. The morphological convergence observed in the jaws of these two distantly related groups of vertebrates may result from similar feeding behaviours. This typical jaw morphology likely represents an effective biomechanical adaptation for biting and grabbing elusive prey items in low-light aquatic environments. Associated with this specialized snout morphology, numerous integumentary mechanoreceptors involved in prey detection are present in both spinosaurs and pike congers. Our new observations provide an additional convincing argument regarding the decades-long and widely debated lifestyle of spinosaurs.

Romain Vullo [romain.vullo@univ-rennes1.fr], Géosciences Rennes, UMR 6118, CNRS, Université de Rennes 1, 263 avenue du Général Leclerc, F-35042 Rennes cedex, France. Ronan Allain [rallain@mnhn.fr], Sorbonne Universités, CR2P, UMR 7207, CNRS, Muséum National d'Histoire Naturelle, Université Paris 06, 57 rue Cuvier, F-75231 Paris cedex 05, France. Lionel Cavin [lionel.cavin@ ville-ge.ch], Muséum d'Histoire Naturelle de Genève, Département de Géologie et Paléontologie, 1 route de Malagnou, CP 6434, CH-1211 Geneva 6, Switzerland.

This is an open-access article distributed under the terms of the Creative Commons Attribution License (for details please see creativecommons.org), which permits unrestricted use, distribution, and reproduction in any medium, provided the original author and source are credited. 
FoF Full text $(248.7 \mathrm{kB})$ 